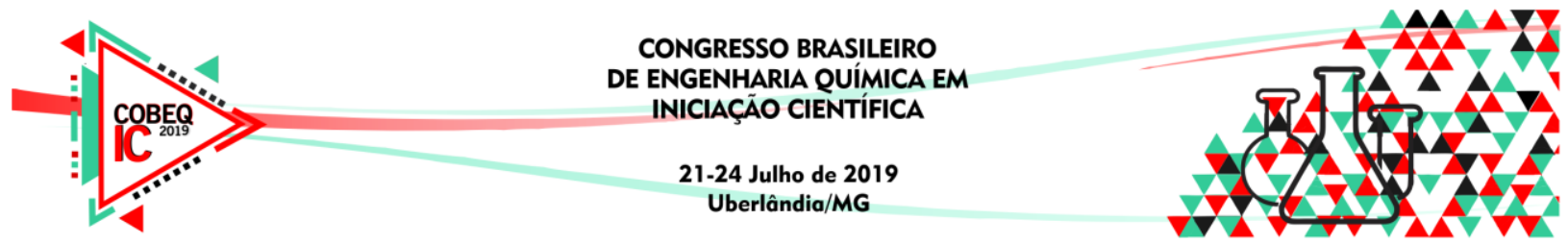

\title{
CARACTERIZAÇÃO DO RESÍDUO DA ERVA MATE PARA UTILIZAÇÃO COMO REFORÇO EM COMPÓSITOS POLIMÉRICOS
}

\author{
K.S.SANTOS ${ }^{1}$ e A. R SENA NETO ${ }^{1}$ \\ ${ }^{1}$ Universidade Federal de Lavras, Departamento de Engenharia \\ E-mail para contato: karolayne.santos2@estudante.ufla.br
}

\begin{abstract}
RESUMO - A busca por compósitos poliméricos mais sustentáveis e ecológicos tem motivado cada vez mais a comunidade científica a procurar novas alternativas para substituir as matérias primas não renováveis usadas como reforço em matrizes poliméricas. Nesse contexto, os resíduos lignocelulósicos são vistos como uma alternativa renovável para reforçar compósitos poliméricos, considerando que são materiais relativamente de baixo valor aquisitivo e encontrados em abundância principalmente nos meios agroflorestais e urbanos. De encontro a essa ideia, o objetivo deste trabalho de iniciação científica é caracterizar o resíduo da erva mate (Ilex paraguariensis) após a sua infusão com foco em suas propriedades, considerando a possibilidade de agregação deste material lignocelulósico como reforço em compósitos poliméricos. Foram caracterizados as composições químicas (extrativos, lignina, holocelulose e celulose) da amostra e também quantificou-se os teores de cinza e umidade. As fibras da erva mate foram submetidas às análises de espectroscopia no infravermelho por transformada de Fourier, difração de raio X, caracterização por termogravimetria e microscopia eletrônica por varredura para melhor visualização da superfície estrutural da amostra.
\end{abstract}

\section{INTRODUÇÃO}

A conscientização que vem crescendo com questões relacionadas ao impacto ambiental e desenvolvimento sustentável tem levado pesquisadores a renovarem o interesse em produzir materiais provenientes de fontes naturais, aumentando a introdução de novas matérias-primas e produtos no mercado (George e Sreekala, 2001).

$\mathrm{Na}$ literatura (Silva et al. 2004), é reconhecido o uso de compósitos poliméricos em aplicações estruturais de médio e grande porte, onde a leveza dessas estruturas vêm acompanhadas de alto desempenho. As fibras utilizadas como reforços nesses materiais são geralmente de origem sintética (vidro, carbono, boro, kevlar) que trazem, portanto, preocupações de caráter ambiental por não serem fibras renováveis.

Diante desse contexto, os materiais compósitos poliméricos reforçados por fibras vegetais vêm sendo investigados, nos últimos anos, pela comunidade científica e industrial na busca de novos materiais que possam substituir eficientemente os materiais sintéticos em 


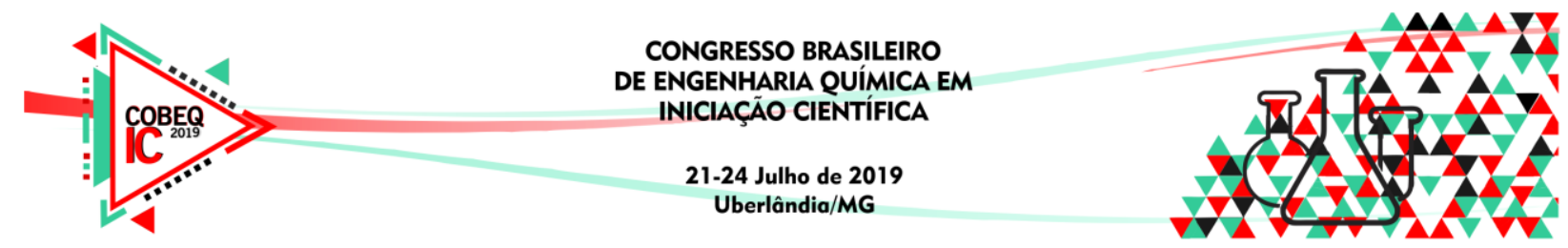

diversas aplicações, principalmente nas indústrias da construção civil, automobilística, aeronáutica e naval.

A substituição de fibras sintéticas por fibras vegetais como agente reforçante em compósitos poliméricos é uma possibilidade atraente segundo os estudos realizados por Joshi et al. (2004), Martins et al. (2004) e Sena Neto (2014), visto que a utilização de fibras vegetais como juta, bambu, linho, algodão, sisal e coco apresentam várias vantagens em relação às fibras inorgânicas, tais como: biodegradabilidade, baixo custo, baixa densidade, boa tenacidade, boas propriedades térmicas e uso reduzido de instrumentos para o seu tratamento ou processamento.

A utilização de fibras vegetais como reforço em matrizes poliméricas favorece aspectos ambientais e econômicos e resulta em novos materiais com propriedades mecânicas satisfatórias, permitindo diferentes aplicações.

De acordo com estudos realizados, fibras vegetais como as da erva mate, apresentam propriedades promissoras quando usadas como reforço em compósitos ou em aglomerados. $\mathrm{O}$ material lignocelulósico obteve sucesso quando incorporado a compósitos de polipropileno, além disso apresenta propriedades físicas e mecânicas de alta performance (Mattos, 2014; Carvalho e Cademartori, 2015).

\section{METODOLOGIA}

Para todas as caracterizações realizadas foram utilizadas amostras de erva mate (Ilex paraguariensis) obtidas no comércio local de Lavras (MG). Antes de qualquer procedimento as amostras passaram por um processo de infusão em água quente para produção do chimarrão, já que o material de interesse nessa pesquisa foi o resíduo da erva mate. Após esse processo as amostras foram acondicionadas em uma estufa à $50^{\circ} \mathrm{C}$ por 24 horas para a secagem completa do material.

A metodologia deste experimento abordou a caracterização do resíduo da erva mate com foco em suas propriedades como possível reforço mecânico em compósitos poliméricos. Dessa forma, esse trabalho foi dividido em três etapas:

Primeira etapa: O material foi obtido no comércio de Lavras e utilizou-se o resíduo da erva mate após infusão em água quente para produção do chimarrão. O material foi homogeneizado em um moinho de facas e peneirado separando a espessura do material de interesse na pesquisa. Após essa etapa ele foi acondicionado em uma estufa para os experimentos seguintes.

Segunda etapa: Foram quantificados os teores de cinzas e umidade do resíduo da erva mate e em sequência foi feita a caracterização química da amostra para quantificar os teores dos constituintes químicos: extrativos, lignina, holocelulose e celulose.

Terceira Etapa: As seguintes propriedades térmicas da amostra foram caracterizadas: termogravimetria, infravermelho e difração por raio X. Além disso, o resíduo teve seu arranjo estrutural analisado por microscopia eletrônica por varredura. 


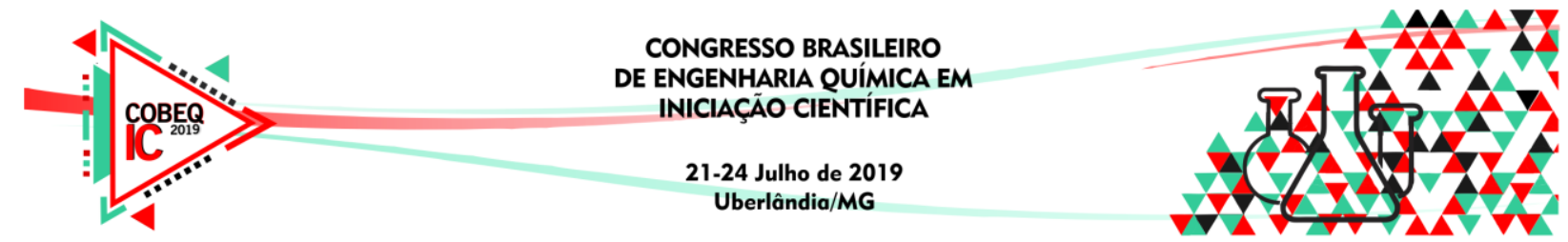

\section{RESULTADOS E DISCUSSÕES}

Como mostra a tabela 1 , o percentual de extrativo do resíduo estudado foi de $26,69 \%$ superior quando comparado ao valor encontrado por Carvalho (2015) para a amostra de resíduo da erva-mate. Os percentis de extrativos dos estudos realizados por este autor variou entre $9,1 \%$ a $14,84 \%$. Esse indicativo demonstra que a metodologia adotada na extração dos extrativos do resíduo da erva mate foi eficiente.

A lignina insolúvel teve percentual de 19,33\% valor este próximo ao encontrado por Carvalho (2015). na amostra de erva mate sem infusão (24,6\%). Os valores de celulose $(22,44 \%)$, hemicelulose $(29,62 \%)$ e holocelulose $(52,06 \%)$, apresentaram valores semelhantes aos apresentados por Freitas et al. (2011) que foram: celulose 21,42\%, hemicelulose $27 \%$ e holocelulose $48,42 \%$.

Tabela 1 - Teores constituintes químicos das fibras

\begin{tabular}{|c|c|c|c|c|c|c|c|}
\hline Amostra & $\begin{array}{c}\text { Umidade } \\
(\%)\end{array}$ & $\begin{array}{c}\text { Cinzas } \\
(\%)\end{array}$ & $\begin{array}{c}\text { Extrativos } \\
(\%)\end{array}$ & $\begin{array}{c}\text { Lignina } \\
(\%)\end{array}$ & & \multicolumn{2}{|c|}{ Holocelulose(\%) } \\
\hline $\begin{array}{c}\text { Resíduo } \\
\text { da erva } \\
\text { mate }\end{array}$
\end{tabular}

Para identificação dos grupos funcionais químicos, característicos do resíduo da erva mate, foram feitas análises espectroscópicas no infravermelho (FTIR) por transmitância, como mostra a figura 2. Estas identificações de picos foram comparadas com os resultados obtidos por outros autores em trabalhos similares. Os picos identificados no espectro $\mathrm{C}-\mathrm{H}$, O$\mathrm{H}, \mathrm{C}=\mathrm{O}, \mathrm{C}=\mathrm{C}, \mathrm{C}-\mathrm{C}, \mathrm{C}-\mathrm{H}$ e C-O são similares aos picos obtidos por outros autores em outras variedades de fibras lignocelulósicas (Candido, 2014).

Figura 1 - Espectro no infravermelho do resíduo da erva mate

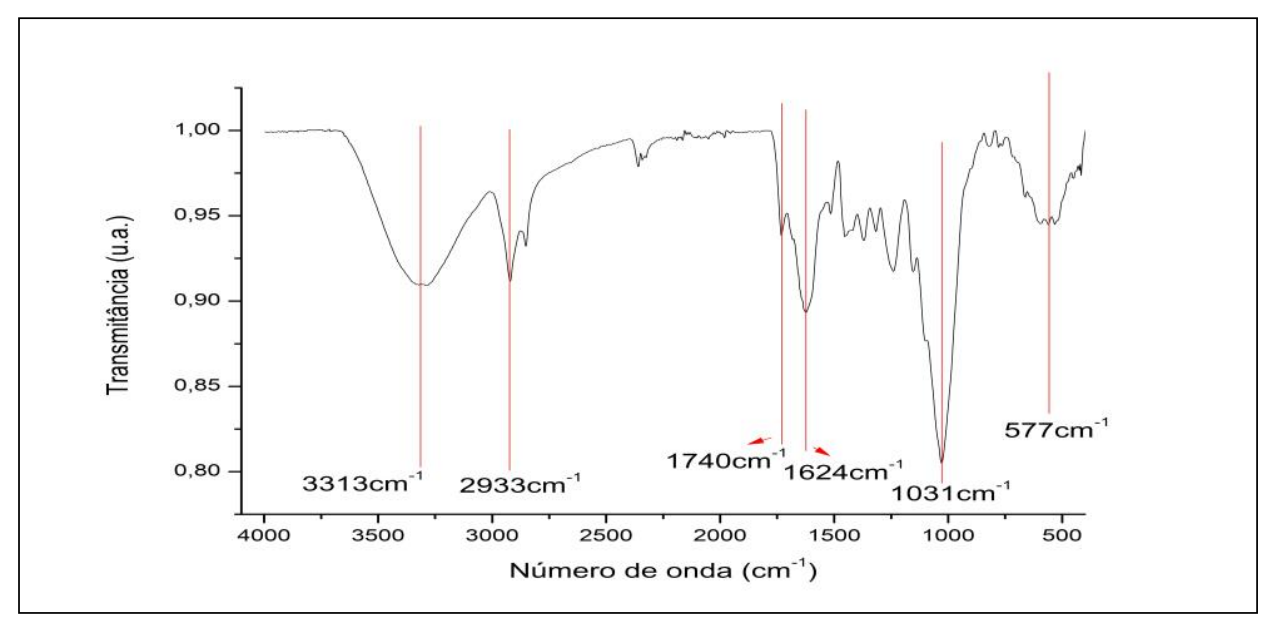




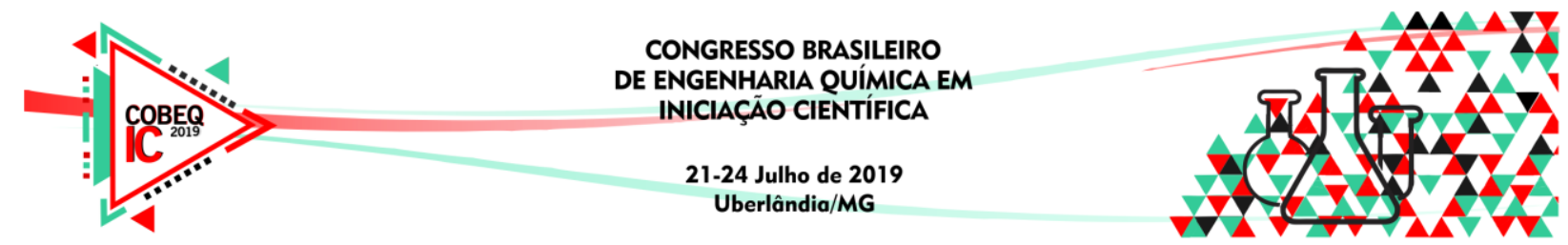

Na difração dos raio x (DRX), o difratograma obtido para a amostra do resíduo da erva mate na figura 2 foi semelhante a outros difratogramas obtidos por autores que usaram variedades diferentes de fibras lignocelulósicas como sisal e folha de abacaxi (Sena Neto 2014; Martin et al., 2009). O resíduo da erva mate apresentou índice de cristalinidade da celulose igual a $6 \%$. Esse valor foi inferior quando comparado com o índice de cristalinidade de outras fibras lignocelulósicas como a de sisal (58 a 61\%) e fibra de coco (43\% a 44\%), (Martin et al., 2009).

Figura 2 - Difratograma de raios $\mathrm{X}$ do resíduo da erva mate

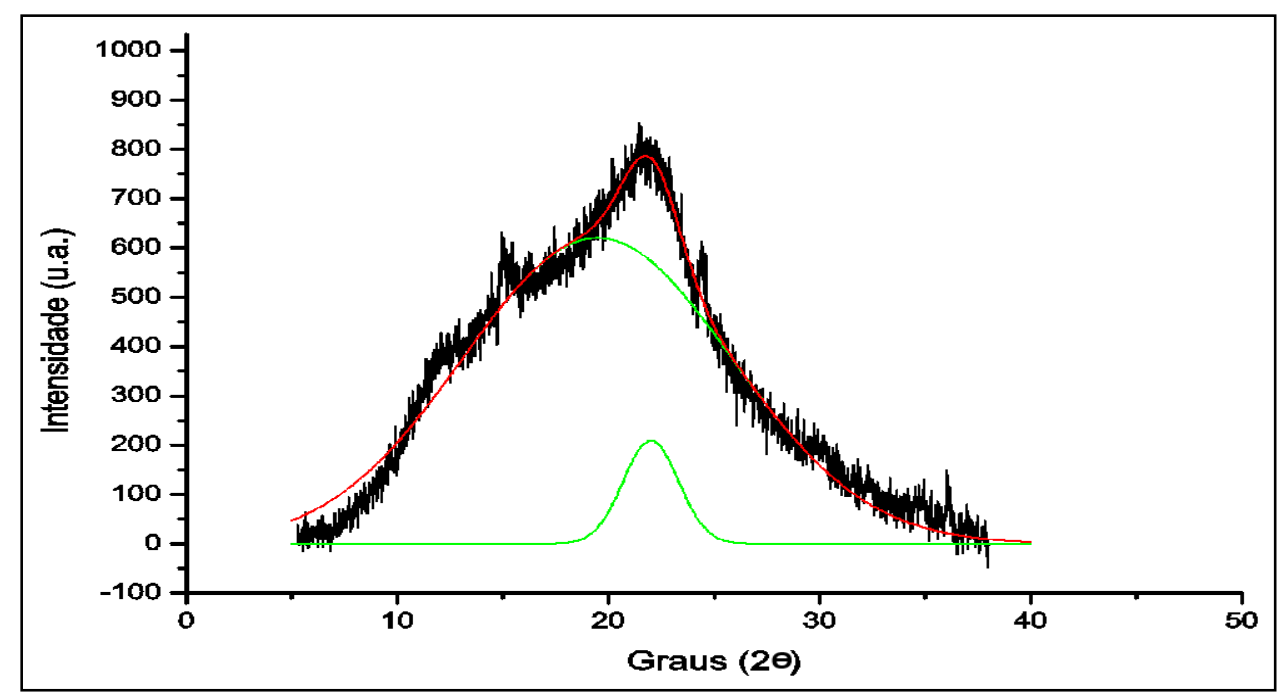

Através da caracterização por termogravimetria (TG) vide figura 3, foi possível identificar dois pontos importantes que servem como referência para utilização de materiais lignocelulósicos na produção de compósitos poliméricos sob temperatura elevada (Martin et al., 2009 ; Mattos 2014). O primeiro ponto é o IDT que representa a temperatura de início de perda de massa por decomposição termooxidativa. O segundo ponto importante a destacar é o OOT que é a temperatura onset de oxidação. Ela é a temperatura máxima na qual uma fibra pode ser submetida no processamento de compósitos poliméricos. Nesse projeto obteve-se as temperaturas de $150^{\circ} \mathrm{C}$ na IDT e $225^{\circ} \mathrm{C}$ na OOT para a amostra do resíduo da erva mate.

Figura 3 - Curva da TG do resíduo da erva mate

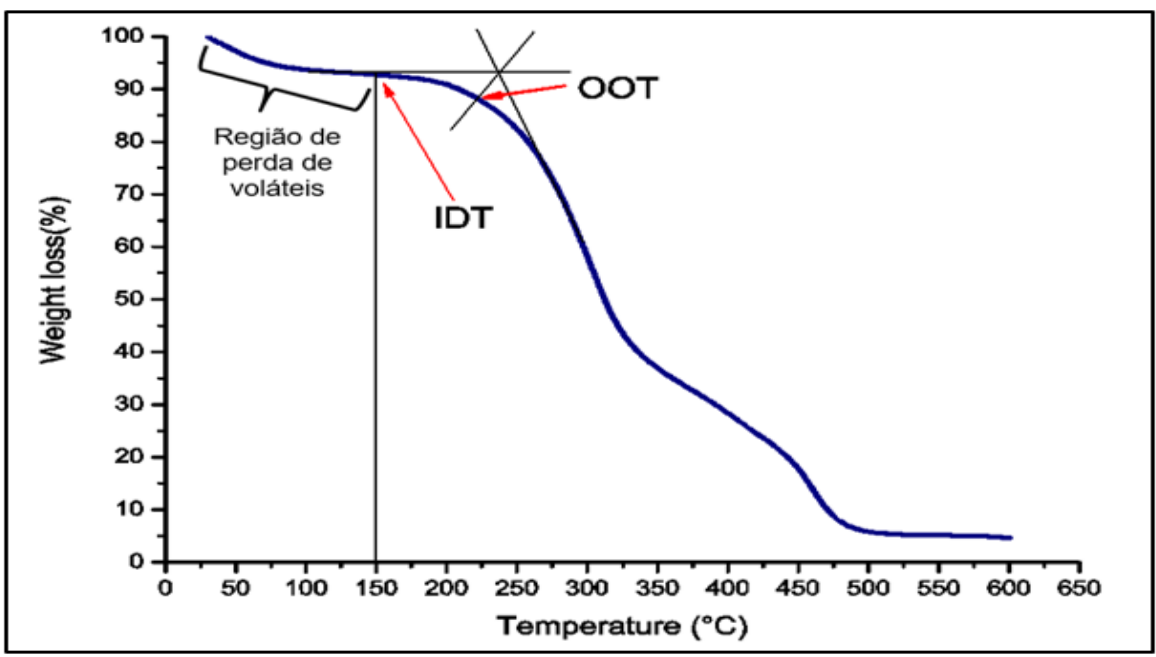




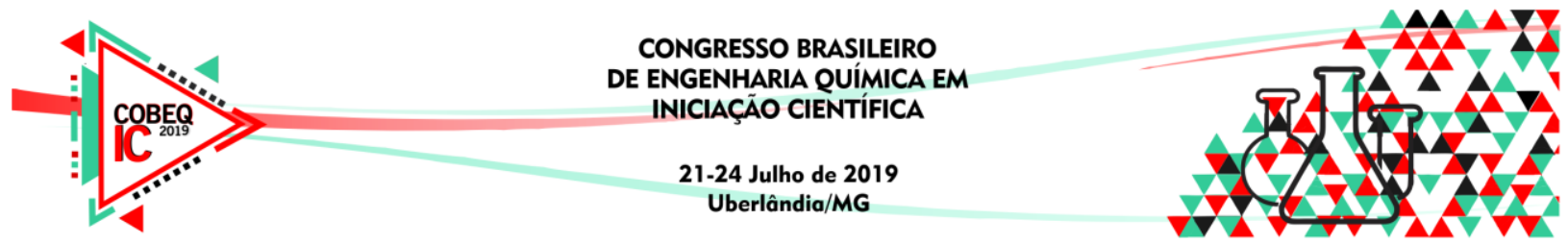

Com a microscopia eletrônica por varredura (MEV) - Figura 4, pode-se observar através da imagem que a superfície da amostra é extremamente rugosa e apresenta muitas estruturas incrustadas a ela. Essas estruturas são indícios de extrativos presentes nas fibras e como estão em grande quantidade comprovam o que foi visto anteriormente na caracterização química, onde o teor de extrativos foi de $26,69 \%$ um valor relativamente alto em comparação com outros materiais lignocelulósicos como a fibra de banana $(5,39 \%)$, fibra de coco $(1,47 \%)$, fibra de sisal (4,01\%), fibra de curauá (12,51\%) e a fibra de taboa (3,04\%), (Pires 2009). Além disso, essas rugosidades presentes na amostra faz com que haja mais interação em à fibra e a matriz polimérica, o que consequentemente aumenta o reforço da fibra.

Figura 4 - Fotomicrografia do resíduo da erva mate

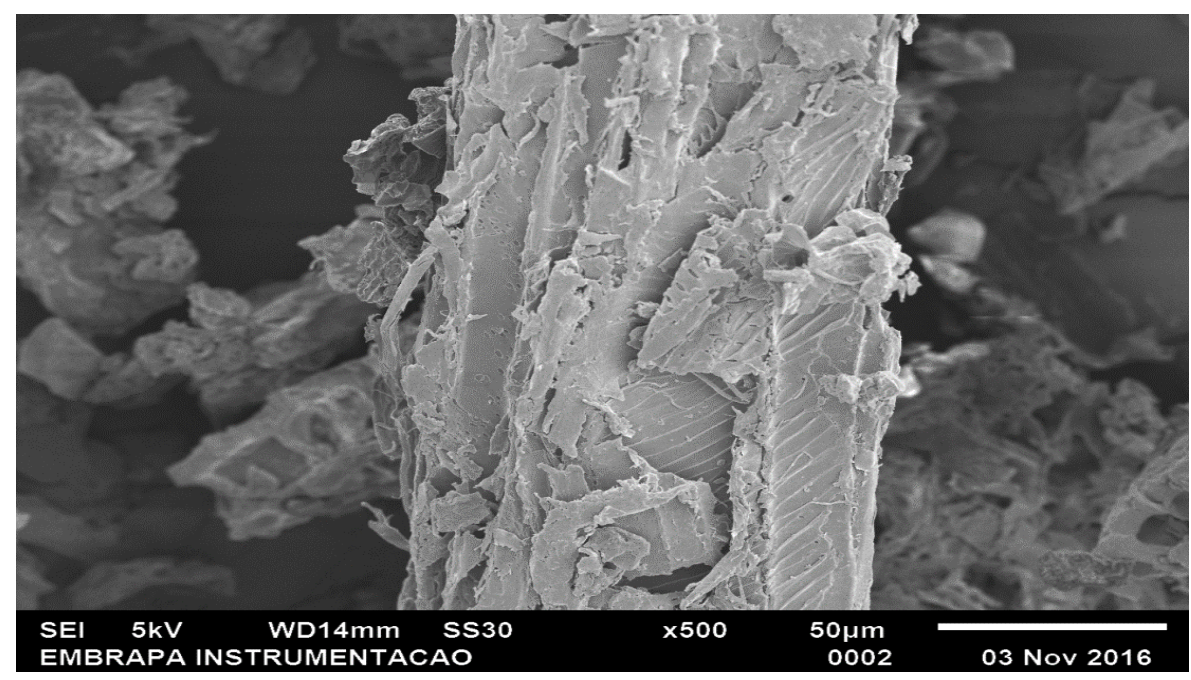

\section{CONCLUSÕES}

Existem poucos estudos relacionados a erva mate dentro da comunidade científica e nenhum explorou o uso do resíduo dessa fibra como possível reforço mecânico em compósitos por extrusão.

O resíduo da erva mate apresentou um alto teor de extrativos isso foi comprovado ao observar as imagens no MEV, as rugosidades existentes indicam que a fibra poderá ter maior adesão a matriz polimérica resultando assim em um maior reforço mecânico.

A temperatura onset de oxidação (OOT) na $\mathrm{TG}$ foi de $225^{\circ} \mathrm{C}$, essa temperatura foi similar a outras temperaturas de variedades diferentes de fibras lignocelulósicas usadas como reforço em compósitos, sendo assim, o resíduo da erva mate possui potencial para ser usado como agente reforçante em matrizes poliméricas.

\section{REFERÊNCIAS}

CADEMARTORI, P. H. Roughness and color evaluation of wood polymer composites filled by household waste of mate-tea. Maderas. Ciencia Y Tecnología, 17, 2015. Acesso em 15 de 06 de 2017, disponível em https://doi.org/10.4067/S0718-221X2015005000041. 


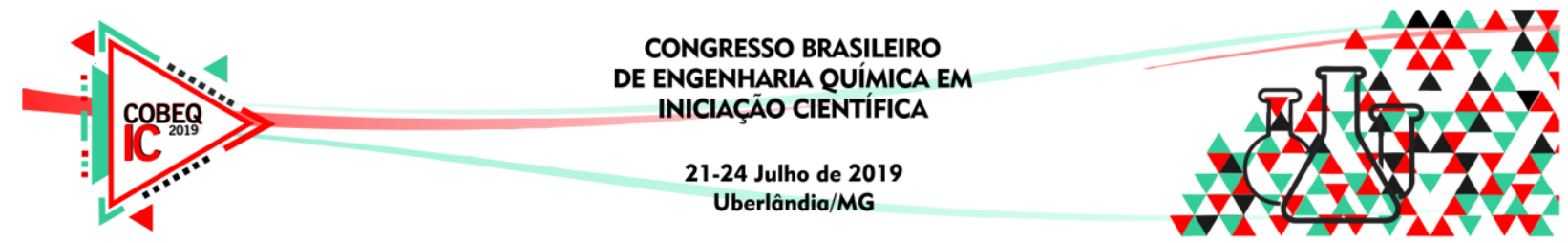

CANDIDO, V. Caracterização e propriedades de compósitos poliméricos reforçados com fibras de bagaço de cana-de-açúcar. Curso de Doutorado em Ciências dos Materiais, Instituto Militar de Engenharia, Exército Brasileiro, 189, 2014.

CARVALHO, A. G. Effect of adding yerba mate pruning residues in particle board panels. Revista Árvore, 209-214, 2015. Acesso em 16 de 05 de 2017, disponível em https://doi.org/http://dx.doi.org/10.1590/0100-67622015000100020

FREITAS, M. Caracterização e pirólise de resíduos de chá-mate tostado para obtenção de biocarvão. IX EBSH, 2011.

GEORGE, J.; SREEKALA, M. A review on interface modification and characterization of natural fiber reinforced plastic composites. Polymer Enginnering Science, 2001.

JOSHI, S. V.; DRZAL, L. T; MOHANTY, A. K; ARORA, S. Are natural fiber composites environmentally superior to glass fiber reinforced composites? Composites Part A: Applied science and manufacturing, v. 35, n. 3, p. 371-376, 2004.

MARTIN, A.; MALTOSO, M.; SILVA, O. Caracterização química e estrutural de fibra de sisal da variedade Agave sisalana. Polímeros: Ciência e Tecnologia, 19(1), 40-46, 2009.

MARTINS, M. A.; KIYOHARA, P. K; JOEKES, I. Scanning electron microscopy study of raw and chemically modified sisal fibers. Journal of applied polymer science, v. 94, n. 6, p. 2333-2340, 2004.

MATTOS, B. Properties of polypropylene composites filled with a mixture of household waste of mate-tea and wood particles. Construction and Building Materials, 2014.

PIRES, J. Fibras naturais: Características Químicas e potenciais aplicações. Trabalho de Conclusão de Curso, Universidade Estadual Paulista Júlio de Mesquita Filho, p. 60, 2009.

SENA NETO A R, "Estudo de fibras de folhas de abacaxis (gênero ananas) e sua utilização em compósitos biodegradáveis com matriz de poli (ácido láctico) (PLA)”. Programa de Pós-graduação em ciência e engenharia de materiais, UFSCar, 2014.

SILVA, C.; FREIRE JÚNIOR, R.; AQUINO, E. Influência da presença de fibras naturais em compósitos híbridos, tipo sanduíche. Universidade Federal do Rio Grande do Norte, 1-2, 2004. 